\title{
Proton Bound Homodimers and Heterodimers of Amides and Amines in the Gas Phase. Equilibrium Studies by Fourier Transform Ion Cyclotron Resonance Spectrometry
}

\author{
Matthias Witt and Hans-Friedrich Grützmacher \\ Fakultät für Chemie, Universität Bielefeld, Bielefeld, Germany
}

\begin{abstract}
By injection of the proton bound homodimer $\left[\mathrm{DMF} \cdot \mathrm{H}^{+} \cdot \mathrm{DMF}\right]$ of $\mathrm{N}, \mathrm{N}$-dimethylformamide (DMF) generated in an external ion source into a mixture of DMF and a second base within the cell of a Fourier transform ion cyclotron resonance (FT-ICR) spectrometer the equilibria between $\left[\mathrm{DMF} \cdot \mathrm{H}^{+} \cdot \mathrm{DMF}\right]$ and the other possible proton bound dimers $\left[\mathrm{DMF} \cdot \mathrm{H}^{+} \cdot\right.$ base] and [base $\mathrm{H}^{+}$.base] have been studied for 13 different bases. Strongly polar bases like aliphatic amides and dimethyl sulfoxide (DMSO) exchange both DMF in [DMF $\mathrm{H}^{+} \cdot \mathrm{DMF}$ ] by a two step process, while the almost non-polar amines exchange only one DMF. If the base is a primary or secondary amine, the proton bound heterodimer [DMF $\mathrm{H}^{+} \cdot$ amine] reacts further by the addition of one DMF to create a proton bound trimer [(DMF $)_{2} \cdot \mathrm{H}^{+} \cdot$ amine]. The affinity $\Delta \mathrm{G}_{\mathrm{DMFH}}$ of the bases towards protonated DMF relative to neutral DMF depends linearly on the difference $\Delta \mathrm{GB}$ of the gas phase basicity of DMF and the other base, but different correlation lines are obtained for polar and non-polar ligands $\left(\Delta \mathrm{G}_{\mathrm{DMFH}+}=0.44 \mathrm{~GB}\right.$ (base) -375 $[\mathrm{kJ} / \mathrm{mol}](\mathrm{r}=0.97)$ and $\Delta \mathrm{G}_{\mathrm{DMFH}+}=0.46 \mathrm{~GB}(\mathrm{base})-397[\mathrm{~kJ} / \mathrm{mol}](\mathrm{r}=0.99)$, respectively). This different behavior is explained by a different character of the proton bridge in the heterodimers containing only polar ligands and those incorporating a non-polar ligand besides DMF. The former dimers contain a more or less symmetric proton bridge while the latter can be viewed as a protonated base solvated by DMF. The available data have been used to calculate the molecular pair gas phase basicity of DMF and the 13 bases used and to estimate the dissociation energies of the bonds of the proton bridge in various proton bound heterodimers. (J Am Soc Mass Spectrom 2002, 13, 1273-1281) () 2002 American Society for Mass Spectrometry
\end{abstract}

$\mathrm{T}$ he properties of proton bound homodimers [amide1 $\cdot \mathrm{H}^{+} \cdot$ amide1] and heterodimers [amide1 $\cdot$ $\mathrm{H}^{+}$amide2] of aliphatic amides, in which two molecules of the same and two molecules of different amides, respectively, are bound by a proton, as well as the properties of proton bound heterodimers [amide $\cdot \mathrm{H}^{+} \cdot$ amine] of amides and amines and other related proton bound amide clusters are of special interest. The amide group corresponds to the peptide bond in proteins, and it is well known [1] that many properties of these macromolecular biomolecules depend on their ability to acquire intra- and intermolecular hydrogen bonds and proton bonds, which involve peptide bonds and other functional groups of the protein like amino or carboxyl groups. In particular, the presumably stronger proton bond, as the charged ana$\log$ of a hydrogen bond, between peptide bonds and

Published online September 17, 2002

Address reprint requests to Dr. H.-F. Grützmacher, Fakultät für Chemie, Universität Bielefeld, P.O. Box 100131, D-33501 Bielefeld, Germany. E-mail: hans-friedrich.gruetzmacher@uni-bielefeld.de basic functional groups is of importance for the enzymatic activity of proteins, which frequently involves a proton release to a proton bound substrate [2]. Further, hydrogen bonds and proton bonds make a fundamental contribution to the stability of the tertiary structure of a protein, and any change of the conformation of the protein is associated with the breaking and making of hydrogen bonds and proton bonds.

Protonated proteins in the gas phase are the objects of many studies in mass spectrometry, since the ability to generate and fragment these ions in the gas phase is essential for the application of mass spectrometry to protein analysis [3]. Another subject of active research during the last years is the determination of the conformation of protonated proteins in the gas phase by mass spectrometric techniques and the search for a correlation between these conformations and tertiary protein structures in solution [4]. These studies revealed that conformational changes of (protonated) proteins are very complex processes and many interesting models such as "mobile protons in proteins" or "stabilization by salt-bridges" have been developed to explain the 
experimental results. Although a careful mass spectrometric investigation of especially designed peptides and proteins is indispensable to make progress in the understanding of proton induced reactions of these biomolecules, in view of the complexity of these reactions considerable support can also be obtained by a study of more elementary model systems. Thus, the protonation of simple amino acid derivatives and amides as well as the formation of proton bound dimers of these species have been studied by high pressure mass spectrometry [5]. In this context the investigation of proton bound clusters of amides are of special interest. The determination of the dissociation energy of homo- or heterodimers of amides gives access to the strength of a proton bond involving peptide groups, and the migration of a proton by hopping from one peptide bond to the other or to suitable functional groups in a protein is simulated by the exchange of ligands in a proton bound amide cluster. The dynamics of this intermolecular process are much more readily observed and experimentally analyzed than the intramolecular migration of the proton in a protein. Further, the structures of aliphatic amides and polyamides can be varied almost at will, and this allows the study of the effect of subtle structural and conformational variations on the properties of proton bound amide clusters.

Proton bound dimers of aliphatic amides are conveniently prepared in the gas phase under the condition of chemical ionization (CI). CI of a mixture of an amide and a suitable base using methane or isobutane as the CI gas efficiently generates the corresponding proton bound heterodimers. This has been used to determine the gas phase basicity (GB) and proton affinity (PA) of a series of amides [6] and diamides [7] by the kinetic method [8]. The results show a structural dependence of PA(amide) typical of other aliphatic carbonyl compounds, in line with a protonation of the amide at the carbonyl-O atom as expected from theoretical calculation. In the case of diamides an increase of the PA by about $80 \mathrm{~kJ} / \mathrm{mol}$ for primary amides and of $50 \mathrm{~kJ} / \mathrm{mol}$ for tertiary $\mathrm{N}, \mathrm{N}$-dimethyl amides as well as entropic effects were observed, if the diamide can form an intramolecular proton bridge [7]. Increasing the partial pressure of the amide in the CI ion source yields the proton bound homodimer, and the investigation of the dissociation of homo- and heterodimers of amides using a modification suitable for FT-ICR spectrometry [9] of the method of collision energy resolved mass spectrometry (CERMS) developed by Armentrout et al. [10] yielded values for the bond dissociation energy (BDE) of proton bonds [6]. The BDE of the proton bond in homodimers of simple aliphatic amides is almost constant with a value of $1.20 \mathrm{eV}(116 \mathrm{~kJ} / \mathrm{mol})$ for primary amides and $1.12 \mathrm{eV}$ $(108 \mathrm{~kJ} / \mathrm{mol})$ for tertiary $\mathrm{N}, \mathrm{N}$-dimethyl amides. The absence of structural effects on the BDE of proton bound homodimers has already been reported for ethers and alcohols [11]. In the case of amides the BDE appears to be sensitive to steric effects if amides with bulky pivalyl groups are analyzed [6]. Further, the BDE of heterodimers between amides and amides or amines is significantly smaller and exhibits a clear dependence on the relative PA of the components [6], as in the case of proton bound dimers of ethers and alcohols.

Besides the energetics of protonation of amides and diamides the reactions of proton bound clusters of amides were studied by FT-ICR spectrometry [12]. In this paper we report and discuss the results of an investigation of the ligand exchange reaction of proton bound clusters of amides with bases using reversible reaction conditions. This results in the formation of all possible homo- and heterodimers at equilibrium with each other and can be used to determine the molecular pair proton affinity (MPPA) of the species taking part in the reaction system and other related data. Since reversible reaction conditions imply that the gas phase within the ICR cell includes the neutral amide at an adequate partial pressure, only the stable and sufficiently volatile amides N-methyl formamide (NMF), $\mathrm{N}, \mathrm{N}$-dimethyl formamide (DMF), acetamide (ACA), and $\mathrm{N}, \mathrm{N}$-dimethylactamide (DMA) were used. Further publications will deal with the ligand exchange reactions of proton bound clusters of amides under the condition ensuing irreversible reactions, which allows the study of a greater variety of amides and diamides, and which gives insight into the dynamics of the making and breaking of proton bridges involving the peptide bond [13].

\section{Experimental}

The amides NMF, DMF, ACA, and DMA as well as the aliphatic amines, pyridines, and DMSO used as ligands in this study are commercially available as pure compounds (purity of all compounds $>99 \%$ ) and were used without further purification.

A Bruker Spectrospin CMS47X FT-ICR (Fällanden, Switzerland) spectrometer was used for all experiments. This instrument is equipped with an external electron impact ionization (EI) ion source and a chemical ionization (CI) ion source, a 4.7 tesla superconducting magnet [14], and an Infinity ${ }^{R}$ ICR cell [15]. The temperature of the external CI ion source was about 200 ${ }^{\circ} \mathrm{C}$ while the ICR cell was kept at room temperature during all experiments. To prepare proton bound homodimers of the amides these were introduced into the $\mathrm{CI}$ ion source by a heated reservoir of the inlet system for liquids and a temperature controlled probe for solid samples, respectively, and isobutane was used as the CI gas at a pressure of 6-15 mbar. The primary ionization of the CI plasma was achieved by $20-30 \mathrm{eV}$ electrons. The ions formed in the external CI ion source including protonated monomers and proton bound clusters were focused for $50-100 \mathrm{~ms}$ into the Infinity ${ }^{\mathrm{R}}$ ICR cell and trapped using a trapping voltage of $1 \mathrm{~V}$. All ions besides the ion selected for the experiment were eliminated from the ICR cell by a broad band $r f$ pulse ("broad band ejection") of about 80VP-P and a length 60-80 $\mu$ s for ions with $m / z$ values sufficiently different from that of the selected ion. This was followed by a series of single $r f$ pulses of appropriate frequency ("single shots") with 10-15 VP-P and a length of 1500-3500 $\mu$ s for ions with 
$m / z$ values close to that of the selected ion. Next, the trapped ions were cooled by collision with Ar atoms introduced into the cell by 3-5 subsequent pressure pulses of $5 \mathrm{~ms}$ duration and a pressure of Ar of $10 \mathrm{mbar}$ in the gas reservoir of the inlet system. After a cooling period of about $200 \mathrm{~ms}$ and a further cleaning step by $r f$ pulses to remove product ions generated during the cooling period the reaction of the selected ions with the neutral reactants present in the ICR cell at an appropriate constant background pressure of $1 \times 10^{-8}-8 \times 10^{-7}$ mbar was observed by taking mass spectra at different reaction times and constructing therefrom the curves of the dependence of the relative ion intensity on reaction time (kinetic plots) for reactant ion and product ions using the curve fitting facilities of the Origin program [16]. The reaction was followed for at least $50 \mathrm{~s}$, and during this time usually the equilibrium (or a steady state) between the different proton bound clusters within the cell was established. The equilibrium constants were calculated from the relative intensity of the ions at this reaction stage and the partial pressure of the neutral reactants within the ICR cell.

The neutral reactants for the ligand exchange reaction were introduced into the ICR cell from a batch inlet system with precision valves and using carefully degassed liquid samples. The composition of mixtures was determined by introducing the components by subsequently opening the valves of the respective reservoirs and waiting to ensure a steady flow of reactants through the ICR cell. Then, the pressure within the ICR cell was obtained from the reading of the ionization gauge positioned between ICR cell and the high vacuum pump of the cell. The reading of the ionization gauge was calibrated by determination of the well established rate constant of the reaction $\mathrm{NH}_{3}^{+}+\mathrm{NH}_{3}->\mathrm{NH}_{4}^{+}+\mathrm{NH}_{2}$ [17]. Further, the appropriate compound specific corrections for the sensitivity of the ionization gauge were used [18]. In the present work a mixture of DMF and the base used for ligand exchange was always used, and a relative concentration of the components was chosen which enabled a reliable determination of the relative intensities of the pertinent ions within the rather small dynamic range of the FT-ICR instrument. This optimal concentration ratio was determined in preliminary experiments. The main error in the determination of the equilibrium constants $K$ from the kinetic plots results

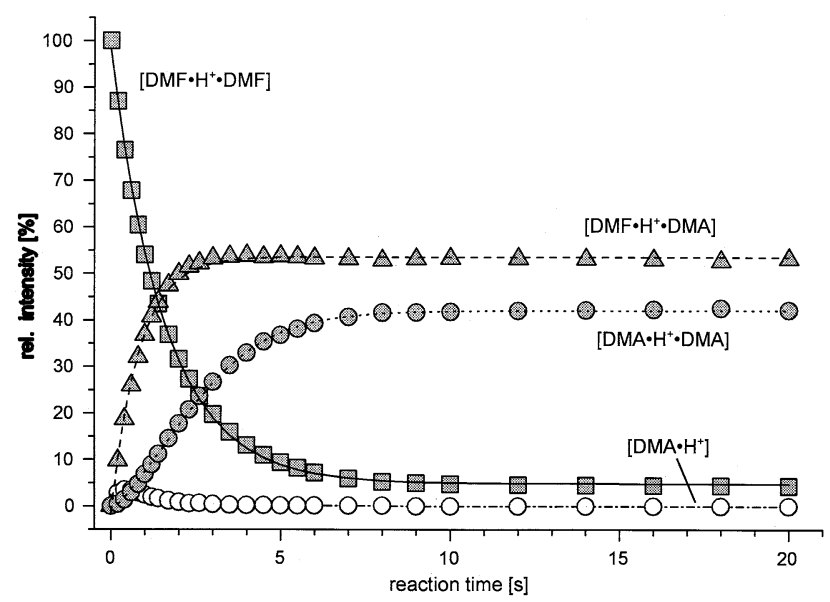

Figure 1. Kinetic plot for the reaction of $\left[\mathrm{DMF} \cdot \mathrm{H}^{+} \cdot \mathrm{DMF}\right]$ with DMF/DMA.

from the error of measurement of the individual partial pressure of the neutral components of the gaseous mixtures. An error of $20 \%$ was estimated for the pressure determination which leads to an error of $50 \%$ of $K$ and about $1 \mathrm{~kJ} / \mathrm{mol}$ of the value of the corresponding $\Delta \mathrm{G}$.

\section{Results and Discussion}

The proton bound homodimer $\left[\mathrm{DMF} \cdot \mathrm{H}^{+} \cdot \mathrm{DMF}\right]$ of $\mathrm{DMF}$ generated in the external ion source of the FT-ICR instrument was always used to initiate the study of equilibrium between this homodimer and hetero- and homodimers containing a second base present in the gas phase of the ICR cell besides DMF. The data show that the bases used for ligand exchange can be arranged in two series of compounds which behave differently in the ligand exchange reaction with $\left[\mathrm{DMF} \cdot \mathrm{H}^{+} \cdot \mathrm{DMF}\right]$. The first series contains polar compounds NMF, ACA, DMA, and DMSO which all exhibit a considerable dipole moment. A typical example is the exchange of the DMF ligands of [DMFH $\left.{ }^{+} \mathrm{DMF}\right]$ by DMA. The kinetic plot of this reaction is shown in Figure 1. The intensity of $\left[\mathrm{DMF} \cdot \mathrm{H}^{+} \cdot \mathrm{DMF}\right]$ decreases rapidly if this homodimer is exposed to a gaseous mixture of DMF and DMA, and the proton bound heterodimer [DMF $\cdot \mathrm{H}^{+} \cdot \mathrm{DMA}$ ] and the homodimer [DMA $\left.\cdot \mathrm{H}^{+} \cdot \mathrm{DMA}\right]$ are formed besides a small amount of protonated DMA. After a few seconds the relative concentrations of these
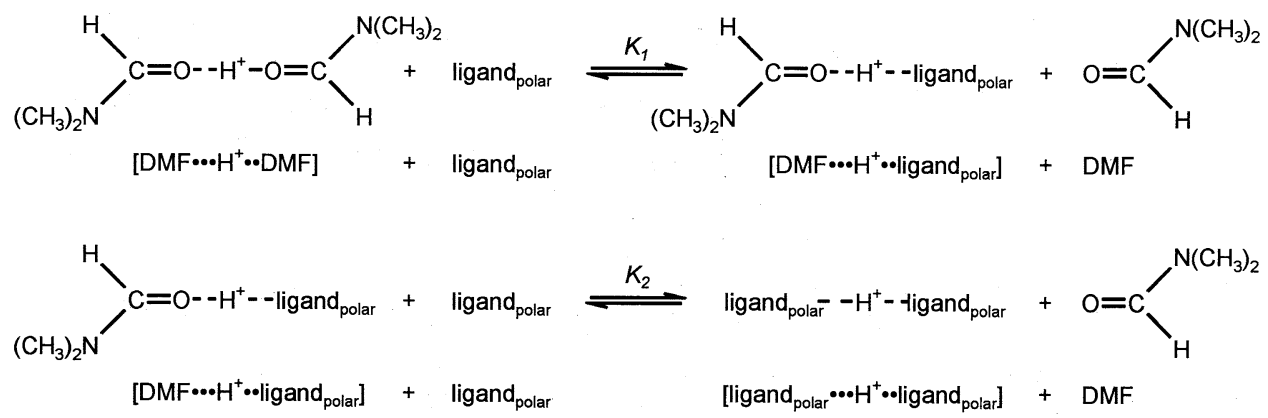

Scheme 1 


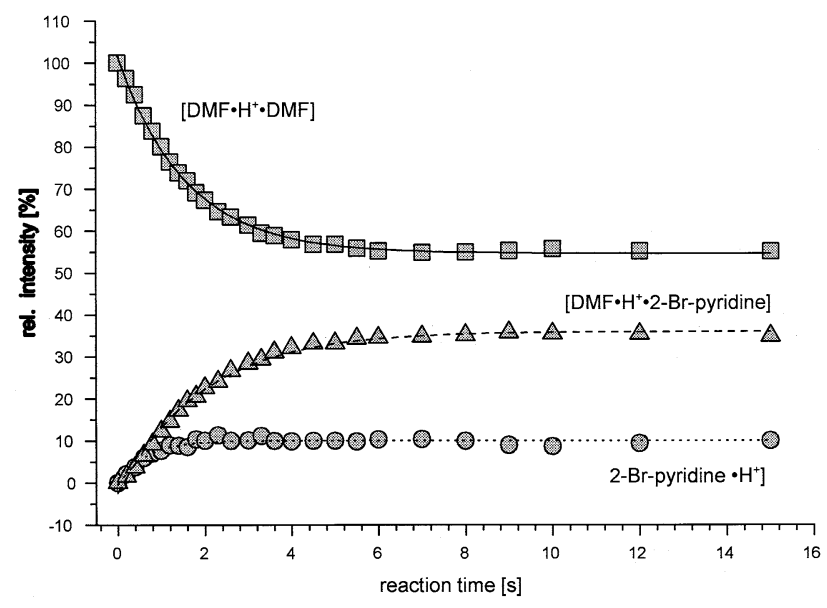

Figure 2. Kinetic plot for the reaction of $\left[\mathrm{DMF} \cdot \mathrm{H}^{+} \cdot \mathrm{DMF}\right]$ with DMF/2-Br-pyridine.

ions become constant and a steady state is reached. The relative concentrations depend on the composition of the neutral gas phase as expected, and the equilibrium constants derived from experiments with mixtures of a different composition agree within the limits of error. This ensures that a true equilibrium is observed in these FT-ICR experiments. The time dependence of the relative concentration of $\left[\mathrm{DMF} \cdot \mathrm{H}^{+} \cdot \mathrm{DMA}\right]$ and $\left[\mathrm{DMA} \cdot \mathrm{H}^{+} \cdot \mathrm{DMA}\right]$ proves unambiguously that the exchange of both DMF ligands occurs in two steps (see Figure 1). This reaction sequences is shown in Scheme $\mathbf{1}$ and is characteristic for this type of ligand exchange of $\left[\mathrm{DMF} \cdot \mathrm{H}^{+} \cdot \mathrm{DMF}\right]$ by polar ligands.

The second series of bases of a quite different behavior consists of ammonia and amines. These compounds exhibit a small dipole moment and exchange only one DMF ligand of [DMF $\left.\mathrm{H}^{+} \cdot \mathrm{DMF}\right]$. As an example the kinetic plot of the ligand exchange by 2-bromopyridine is presented in Figure 2. In this reaction system as well as in the ligand exchange by other tertiary amines the equilibrium mixture of ions consists only of the original proton bound homodimer $\left[\mathrm{DMF} \cdot \mathrm{H}^{+} \cdot \mathrm{DMF}\right]$ and the het-

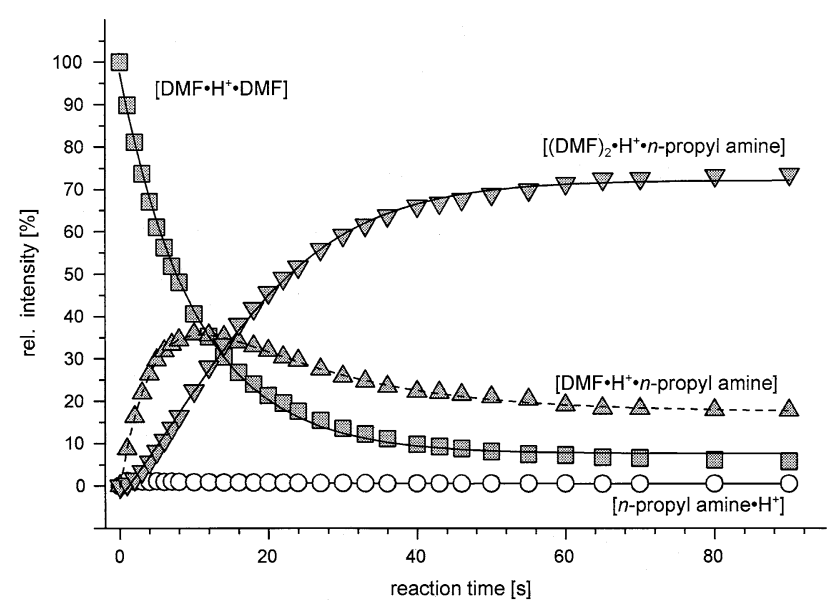

Figure 3. Kinetic plot for the reaction of $\left[\mathrm{DMF} \cdot \mathrm{H}^{+} \cdot \mathrm{DMF}\right]$ with DMF/n-propyl amine.

erodimer [DMF $\cdot \mathrm{H}^{+}$tert $\cdot$ amine] besides some protonated amine. The amount of protonated base is always small $(<15 \%)$ but the origin of the protonated base is not clear. One possibility is a dissociation of $\left[\mathrm{DMF} \cdot \mathrm{H}^{+} \cdot \mathrm{DMF}\right]$ by reaction with the amine during the early stages of the reaction because some $\left[\mathrm{DMF} \cdot \mathrm{H}^{+} \cdot \mathrm{DMF}\right]$ may be still energetically excited in spite of the cooling procedure. The proton stays with the stronger base, and the protonated base undergoes no further reaction. However, more likely the protonated amine stems from a photodissociation of the heterodimer [DMF $\mathrm{H}^{+}$amine] by black body irradiation (BIRD). If a primary or a secondary amine is used for ligand exchange, the heterodimer [DMF $\cdot \mathrm{H}^{+}$amine] generated by the exchange of one DMF ligand undergoes a further reaction by a slow association of a second DMF molecule to produce the proton bound trimer $\left[(\mathrm{DMF})_{2} \cdot \mathrm{H}^{+} \cdot\right.$ amine] (Scheme 2). Further clustering by association of additional molecules of DMF was not observed even for primary amines as ligands which display after protonation a $\mathrm{H}_{3} \mathrm{~N}^{+}$group and which might be expected to bind three DMF molecules by each of the three acidic hydrogen atoms.

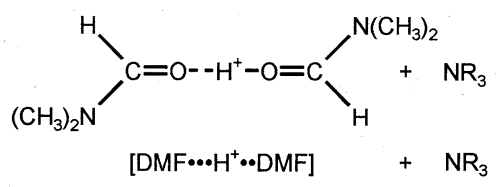<smiles>CN(C)C=O</smiles>

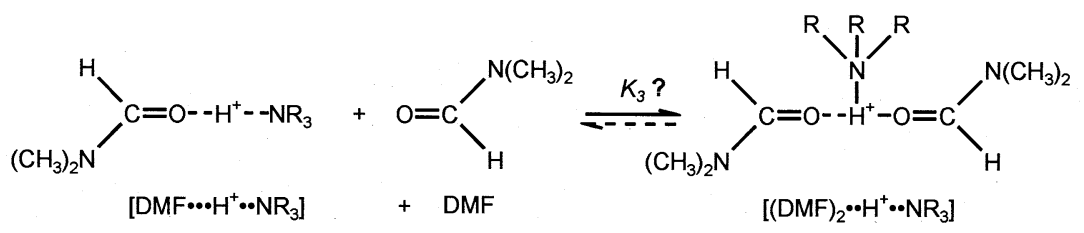

$\mathrm{R}=\mathrm{H}$, Alkyl 
Table 1. Equilibrium constants $\mathrm{K}_{1}$ and $\mathrm{K}_{2}$ of proton bound homo- and heterodimers of DMF and ligands, and relative ligand affinities $\psi \mathrm{G}_{\mathrm{DMFH}+}$ (base)

\begin{tabular}{|c|c|c|c|c|c|c|}
\hline Ligand (base) & $\mathrm{GB}^{\mathrm{a}}$ & $\mathrm{PA}^{\mathrm{a}}$ & $\mu_{D}^{b}$ & $\mathrm{~K}_{1}$ & $\Delta \mathrm{G}_{\mathrm{DMFH}+}$ (base) & $\mathrm{K}_{2}$ \\
\hline $\mathrm{NH}_{3}$ & 819 & 854 & 1.47 & $1.8 \times 10^{-4}$ & -21.5 & - \\
\hline NMF & 820 & 851 & 3.84 & $1.7 \times 10^{-2}$ & -10.2 & $2.5 \times 10^{-3}$ \\
\hline ACA & 833 & 864 & 3.90 & $3.3 \times 10^{-2}$ & -8.5 & $5.5 \times 10^{-3}$ \\
\hline DMSO & 854 & 885 & 3.90 & 1.4 & 0.8 & 0.34 \\
\hline DMF & 855 & 886 & 3.90 & - & 0 & - \\
\hline Methyl amine & 865 & 896 & 1.29 & 2.7 & 2.5 & - \\
\hline 2-Br-pyridine & 867 & 899 & 3.21 & 0.4 & -2.3 & - \\
\hline $\begin{array}{l}\text { c-Propyl } \\
\text { Amine }\end{array}$ & 871 & 905 & 1.30 & 1.3 & 0.7 & - \\
\hline DMA & 877 & 908 & 3.81 & 440 & 15.1 & 31 \\
\hline Ethyl amine & 878 & 912 & 1.22 & 3.3 & 3.0 & - \\
\hline $\begin{array}{l}\text { n-Propyl } \\
\text { Amine }\end{array}$ & 884 & 918 & 1.18 & 21 & 7.6 & - \\
\hline n-Hexyl amine & 887 & 921 & 1.32 & 75 & 10.7 & - \\
\hline $\begin{array}{l}\text { Dimethyl } \\
\text { Amine }\end{array}$ & 897 & 930 & 1.03 & 478 & 15.3 & - \\
\hline Pyridine & 898 & 934 & 2.25 & 1360 & 17.9 & - \\
\hline
\end{tabular}

${ }^{\mathrm{a}} \mathrm{kJ} / \mathrm{mol}$; from Reference [19]

${ }^{b}$ From A. C. McClallan and W. H. Freeman, Table of Experimental Dipole Monents, Vol I. Freeman; San Francisco, 1963.

An example of this type of ligand exchange is shown in Figure 3 by the kinetic plot of ligand exchange reaction of $\left[\mathrm{DMF} \cdot \mathrm{H}^{+} \cdot \mathrm{DMF}\right]$ with n-propyl amine. Since the proton bound heterodimer $\left[\mathrm{DMF} \cdot \mathrm{H}^{+} \cdot \mathrm{n}\right.$-propyl amine] is continuously removed from its equilibrium with $\left[\mathrm{DMF} \cdot \mathrm{H}^{+} \cdot \mathrm{DMF}\right]$, a constant ratio of the relative intensities of these species reflects only a steady state and not an undisturbed equilibrium. However, the association reaction of $\left[\mathrm{DMFH}^{+}\right.$amine] with $\mathrm{DMF}$ is always slow compared to the rate of establishing the equilibrium, so that the disturbance of the equilibrium may be neglected to a first approximation. Accordingly, the equilibrium constant $K_{1}$ between [DMF $\mathrm{H}^{+} \cdot \mathrm{DMF}$ ] and [DMF. $\mathrm{H}^{+}$amine] was derived from the ratio of the relative intensities of these species which becomes constant at the later stages of the reaction. Further, all curves representing the relative intensities of the proton bound clusters appear to reach a constant level at very long reaction times. This agrees with the assumption of a continuous dissociation of the proton bound trimer $\left[(\mathrm{DMF})_{2} \cdot \mathrm{H}^{+}\right.$.amine] by BIRD reforming $\left[\mathrm{DMF} \cdot \mathrm{H}^{+}\right.$. amine] and DMF. The dissociation of proton bound trimers of amines and amides by BIRD and other reactions of the proton bound trimers $\left[(\mathrm{DMF})_{2} \mathrm{H}^{+}\right.$amine] will be discussed in detail in a forthcoming paper [19], but the results clearly prove an effective BIRD of these clusters.

The equilibrium constants $K_{1}$ and $K_{2}$ for the first and second ligand exchange calculated from the kinetic plots of all bases used are collected in Table 1, in which the bases are ordered by increasing GB [20]. $K_{1}$ is a measure of the ability of the base to act as a ligand of the proton bound dimer. As a general trend, $K_{1}$ increases with increasing GB of the attached base, but the polar reactants are obviously not only performing the double ligand exchange but the outstanding values of $K_{1}$ show also that polar molecules are the better ligands. This is conveniently seen by defining a free ligand affinity $\mathrm{G}_{\mathrm{DMFH}}$ (base) and ligand affinity $\mathrm{A}_{\mathrm{DMFH}+}$ (base) of the base towards protonated DMF $\left(=\mathrm{DMFH}^{+}\right)$and using DMF as a reference base to express the competition of DMF and the base for $\mathrm{DMFH}^{+}$in the first step of the ligand exchange equilibrium by $\Delta \mathrm{G}_{\mathrm{DMFH}+}$ (base) or $\Delta \mathrm{A}_{\mathrm{DMFH}+}$ (base). The definitions are given in eq 1 and 2, and the values of $\Delta \mathrm{G}_{\mathrm{DMFH}+}$ (base) are included in Table 1.

$$
\begin{gathered}
\mathrm{DMFH}^{+}+\text {base } \rightarrow\left[\text { DMF. } \mathrm{H}^{+} \cdot \text { base }\right]-\Delta \mathrm{G}_{\mathrm{r}}-\Delta \mathrm{G}_{\mathrm{r}} \\
=\mathrm{G}_{\mathrm{DMFH}+}(\text { base })-\Delta \mathrm{H}_{\mathrm{r}} \\
=\mathrm{A}_{\mathrm{DMFH}+} \text { (base) } \\
\begin{aligned}
\Delta \mathrm{G}_{\mathrm{DMFH}+}(\text { base }) & =\mathrm{G}_{\mathrm{DMFH}+} \text { (base) }-\mathrm{G}_{\mathrm{DMFH}+}(\mathrm{DMF}) \\
& =-\mathrm{RT} \ln K_{l}
\end{aligned}
\end{gathered}
$$$$
\Delta \mathrm{A}_{\mathrm{DMFH}+}(\text { base })=\mathrm{A}_{\mathrm{DMFH}+}(\text { base })-\mathrm{A}_{\mathrm{DMFH}+}(\mathrm{DMF})
$$

A positive and a negative value of $\Delta \mathrm{G}_{\mathrm{DMFH}+}$ (or $\left.\Delta \mathrm{A}_{\mathrm{DMFH}}\right)$ designates a base that is a stronger and a weaker ligand, respectively, than DMF. In Figure 4 $\Delta \mathrm{G}_{\mathrm{DMFH}+}$ is plotted against the $\mathrm{GB}$ (base). This results in two linear correlations $\Delta \mathrm{G}_{\mathrm{DMFH}+}=0.44 \mathrm{~GB}$ (base) -375 $[\mathrm{kJ} / \mathrm{mol}](\mathrm{r}=0.97)$, covering a range of $\mathrm{GB}$ of 60 $\mathrm{kJ} / \mathrm{mol}$, and $\Delta \mathrm{G}_{\mathrm{DMFH}+}=0.46 \mathrm{~GB}$ (base) $-397[\mathrm{~kJ} / \mathrm{mol}]$ $(\mathrm{r}=0.99)$, covering a range of $\mathrm{GB}$ of $80 \mathrm{~kJ} / \mathrm{mol}$, for the series of polar and nonpolar ligands, respectively. Thus, the almost identical slopes of the correlation lines show that both types of ligands display a similar dependence on their GB but there is an offset favoring the binding of 


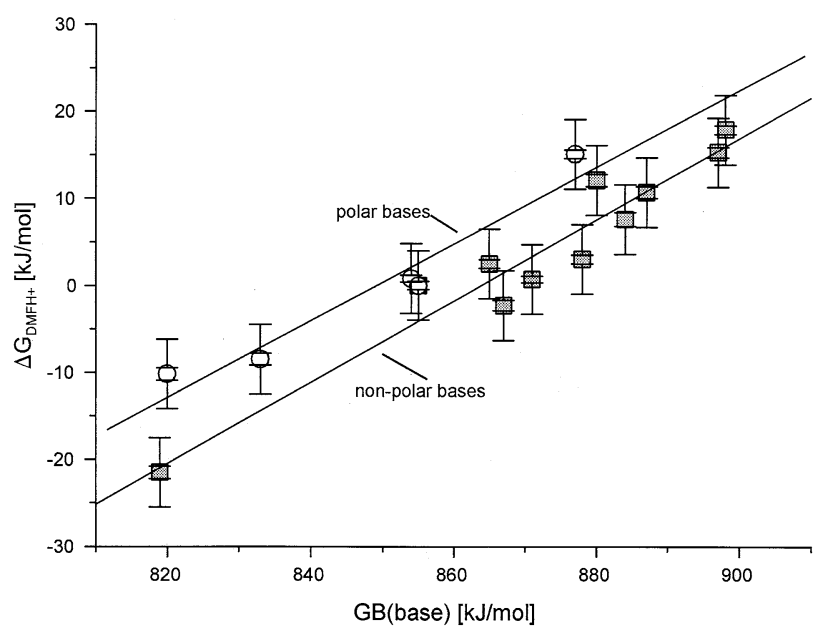

Figure 4. Correlation of relative free ligand affinity $\Delta G_{\mathrm{DMFH}+}$ with GB(base). (Open circle amide; DMSO; filled circle amine).

polar ligands. Evidently, a proton bridge binding the polar DMF and a polar ligand and a proton bridge binding DMF and a nonpolar amine exhibit different properties. [A reviewer raised the point whether this different behavior could indicate different types of a proton bridge, i.e., a proton bridge involving the carbonyl-O atom versus a proton bridge involving the $\mathrm{N}\left(\mathrm{CH}_{3}\right)_{2}$ group of the carboxamide. However, so far theoretical calculation (M. Witt, Reference [13] and private communication) always produce the carbonyl-O bridged species as the stable structure of homodimers of carboxamides, and there are no experimental data which would force the assumption of proton bonding by the carboxamide-N atom.] Inverse linear correlations between the strength of the proton bond in a proton bound heterodimer (or the affinity of a particular ligand to a given protonated species) with the PA difference of the components have been observed before for various systems [5a, 11a, 21]. In the case of proton bound dimers of amines and nitriles it has been found that, for a given protonated amine, the correlation is different for the binding of a non-polar second amine or a polar nitrile [21c], and it was shown that the difference can be semi-quantitatively explained by the stabilization of the proton bound dimer by the electrostatic interaction between the protonated amine and the attached ligand which is considerably stronger for the polar nitrile. This is certainly also a sensible explanation for the different GB correlations observed for the dimers $\left[\mathrm{DMF} \cdot \mathrm{H}^{+}\right.$.amide] and $\left[\mathrm{DMF} \cdot \mathrm{H}^{+} \cdot\right.$ amine]. However, as will be shown in a separate paper [13] both types of dimers exhibit a different dependence of the rate constants for ligand exchange of on the structure of the amide and the ligand. In particular the rate constant of the exchange of the amine in [DMF. $\mathrm{H}^{+}$.amine] is usually large. This agrees with a strongly asymmetric proton bridge in [DMF $\mathrm{H}^{+}$amine] with the proton residing near the more basic amine and the polar DMF acting as a hydrogen bonded solvent molecule. Moreover, this "solvation model" of the proton bound het- erodimers of DMF and amines explains the attachment of a second molecule of DMF, thus increasing the solvent shell. In the likely more symmetric proton bridge between DMF and a polar ligand, the positive charge is distributed over both ligands, and the delocalized charge is less disposed for solvation by polar molecules. $\Delta \mathrm{G}_{\mathrm{DMFH}+}$ and $\Delta \mathrm{A}_{\mathrm{DMFH}+}$ can be used to calculate the relative molecular pair gas phase basicity MPGB and MPPA of DMF and of the ligands used. The definition of MPGB and MPPA are given in eq 3 and the correlation between $\mathrm{GB}(\mathrm{DMF}), \mathrm{GB}$ (base) and $\Delta \mathrm{G}_{\mathrm{DMFH}+}$ or PA(DMF), PA(base) and $\Delta \mathrm{A}_{\mathrm{DMFH}}$ is shown in eq 4 . The MPGBs and MPPAs derived in this way are collected in Table 2. Further, eq 5 and Scheme 3 show that the dissociation energy $\mathrm{BDE}\left(\mathrm{DMFH}^{+}\right.$-ligand) of the proton bond between $\mathrm{DMFH}^{+}$and the ligand can be calculated from $\mathrm{A}_{\mathrm{DMFH}^{+}}$, if $\mathrm{BDE}\left(\mathrm{DMFH}^{+}-\mathrm{DMF}\right)$ of the homodimer is known. This latter value has been determined by CERMS yielding $\mathrm{BDE}\left(\mathrm{DMFH}^{+}-\mathrm{DMF}\right)=1.12$ $\pm 0.06 \mathrm{eV}(108 \pm 6 \mathrm{~kJ} / \mathrm{mol})[6 \mathrm{~b}]$ The BDE(DMFH ${ }^{+}$ligand) calculated by eq 5 with this value of $\mathrm{BD}$ $\mathrm{E}\left(\mathrm{DMFH}^{+}-\mathrm{DMF}\right)$ are included in Table 2. $\left[\Delta \mathrm{A}_{\mathrm{DMFH}}+\right.$ and $\Delta \mathrm{G}_{\mathrm{DMH}+}$ are relative values, and $\Delta \mathrm{A}_{\mathrm{DMFH}+}$ differs from $\Delta \mathrm{G}_{\mathrm{DMH}+}$ by the difference of the entropy changes of the reaction in eq 5 . In analogy to the differences of the entropy of protonation which are usually small for organic molecules, it is expected that this difference is small and can be neglected to a first approximation. Thus, $\Delta \mathrm{A}_{\mathrm{DMFH}}+$ has been represented by the values of $\Delta \mathrm{G}_{\mathrm{DMFH}+}$ for the calculation of $\mathrm{D}\left(\mathrm{DMFH}^{+}\right.$-ligand $)$.]

$$
\begin{aligned}
& \mathrm{DMF}+\mathrm{H}^{+}+\text {base } \rightarrow\left[\mathrm{DMF} \cdot \mathrm{H}^{+} \cdot \text { base }\right] \\
& -\Delta G_{r}=\text { MPGB(DMF,base) } \\
& -\Delta \mathrm{H}_{\mathrm{r}}=\operatorname{MPPA}(\mathrm{DMF}, \mathrm{base}) \\
& \operatorname{MPGB}(\mathrm{DMF}, \mathrm{base})=\operatorname{MPGB}(\mathrm{DMF}, \mathrm{DMF}) \\
& +\Delta \mathrm{G}_{\mathrm{DMFH}+} \\
& \operatorname{MPPA}(\mathrm{DMF}, \mathrm{base})=\operatorname{MPPA}(\mathrm{DMF}, \mathrm{DMF}) \\
& +\Delta \mathrm{A}_{\mathrm{DMFH}}+ \\
& \mathrm{DMFH}^{+}+\mathrm{DMF} \rightarrow\left[\mathrm{DMF} \cdot \mathrm{H}^{+} \cdot \mathrm{DMF}\right]-\Delta \mathrm{G}_{\mathrm{r}} \\
& \left.=\mathrm{BDE}_{(\mathrm{DMFH}}{ }^{+}-\mathrm{DMF}\right]+\mathrm{T} \Delta \mathrm{S}_{\mathrm{DMFH}}+ \\
& \approx \mathrm{BDE}\left(\left[\mathrm{DMFH}^{+}-\mathrm{DMF}\right]+\mathrm{TS}^{\circ}\left(\mathrm{H}^{+}\right) \mathrm{BDE}\left(\mathrm{DMFH}^{+}\right.\right. \\
& \text {- base) } \\
& =\mathrm{BDE}\left(\mathrm{DMFH}^{+}-\mathrm{DMF}\right)+\Delta \mathrm{A}_{\mathrm{DMFH}}+ \\
& \approx \mathrm{BDE}\left(\mathrm{DMFH}^{+}-\mathrm{DMF}\right) \\
& +\Delta \mathrm{G}_{\mathrm{DMFH}+}\left(\text { if } \Delta \Delta \mathrm{S}_{\mathrm{DMFH}+} \approx 0\right)
\end{aligned}
$$

The MPGB of the molecular pairs [DMF, ligand] increase with GB(ligand), but less than GB(ligand) itself. 
Table 2. Molecular pair gas phase basicitiy, (MPGB), molecular pair proton affinity, (MPPA), dissociation energy $\mathrm{D}\left(\mathrm{DMFH}{ }^{+}\right.$-base), dissociation energy $\mathrm{D}\left(\mathrm{DMF}-\mathrm{H}^{+}\right.$base $)$, and total dissociation energy $\mathrm{D}\left(\mathrm{DMF}-\mathrm{H}^{+} \text {-base }\right)_{\text {total }}$ of proton bound homo- and heterodomers of DMF

\begin{tabular}{|c|c|c|c|c|c|c|c|}
\hline Ligand (base) & $\mathrm{GB}^{\mathrm{a}}$ & MPGB $^{a}$ & $P A^{a}$ & MPPA $^{a}$ & $\begin{array}{c}\text { BDE } \\
(\mathrm{DMFH}+- \text { base })^{\mathrm{a}}\end{array}$ & $\begin{array}{c}\text { BDE } \\
\left(\text { DMF- }^{+} \text {base }\right)^{a, b}\end{array}$ & $\begin{array}{c}\mathrm{BDE} \\
\left(\mathrm{DMF}-\mathrm{H}^{+-} \text {-base }\right)_{\text {total }}\end{array}$ \\
\hline $\mathrm{NH}_{3}$ & 819 & 910 & 854 & 973 & 87 & - & - \\
\hline NMF & 820 & 921 & 851 & 984 & 98 & - & - \\
\hline ACA & 833 & 923 & 864 & 985 & 100 & - & - \\
\hline DMSO & 854 & 932 & 885 & 993 & 109 & - & - \\
\hline DMF & 855 & 931 & 886 & 994 & 108 & 108 & 216 \\
\hline Methyl amine & 865 & 934 & 896 & 997 & 111 & 48 & 193 \\
\hline 2-Br-pyridine & 867 & 929 & 899 & 992 & 106 & - & - \\
\hline $\begin{array}{l}\text { c-Propyl } \\
\text { amine }\end{array}$ & 871 & 932 & 905 & 993 & 109 & 86 & 195 \\
\hline DMA & 877 & 946 & 908 & 1009 & 123 & 94 & 217 \\
\hline Ethyl amine & 878 & 934 & 912 & 997 & 111 & 88 & 199 \\
\hline $\begin{array}{l}\text { n-Propyl } \\
\text { amine }\end{array}$ & 884 & 939 & 918 & 1002 & 116 & 102 & 218 \\
\hline n-Hexyl amine & 887 & 942 & 921 & 1005 & 119 & - & - \\
\hline $\begin{array}{l}\text { Dimethyl } \\
\text { amine }\end{array}$ & 897 & 946 & 930 & 1009 & 123 & 102 & 225 \\
\hline Pyridine & 898 & 949 & 934 & 1012 & 126 & - & - \\
\hline
\end{tabular}

${ }^{a} \mathrm{~kJ} / \mathrm{mol}$; from Reference [19].

${ }^{\mathrm{b}} \mathrm{kJ} / \mathrm{mol}$; from References [6] and [12].

This becomes more perceptible from the $\triangle \mathrm{GB}_{\mathrm{MPGB}}$ between MPGB(DMF,ligand) and GB(ligand) shown in the 4th column of Table 2. $\Delta \mathrm{GB}_{\mathrm{MPGB}}$ decreases from about $100 \mathrm{~kJ} / \mathrm{mol}$ for NMF as the ligand to about 50 $\mathrm{kJ} / \mathrm{mol}$ for dimethyl amine and pyridine as the most basic ligands used. Of course, this diminished increase of MPGB(DMF,ligand) is already documented by the factor of 0.44 and 0.46 in the correlation of $\Delta \mathrm{G}_{\mathrm{DMFH}+}$ and GB(ligand), and is readily explained by less accumulation of the positive charge at the base in the proton bound heterodimer [DMF. $\mathrm{H}^{+}$.base] compared to the protonated base itself. This effect is expected both for a proton bound heterodimer in which the proton bond has some covalent character and for a proton bound heterodimer with a structure according to the solvation model. The 6th column of Table 2 shows the $\mathrm{BDE}\left(\mathrm{DMFH}^{+}\right.$-ligand) which increases significantly with GB(ligand) from $87 \mathrm{~kJ} / \mathrm{mol}$ for ammonia to 123 $\mathrm{kJ} / \mathrm{mol}$ for pyridine. It should be noted that BD$\mathrm{E}\left(\mathrm{DMFH}^{+}\right.$-ligand) is always associated with the dissociation of the proton bound heterodimer into $\mathrm{DMFH}^{+}$

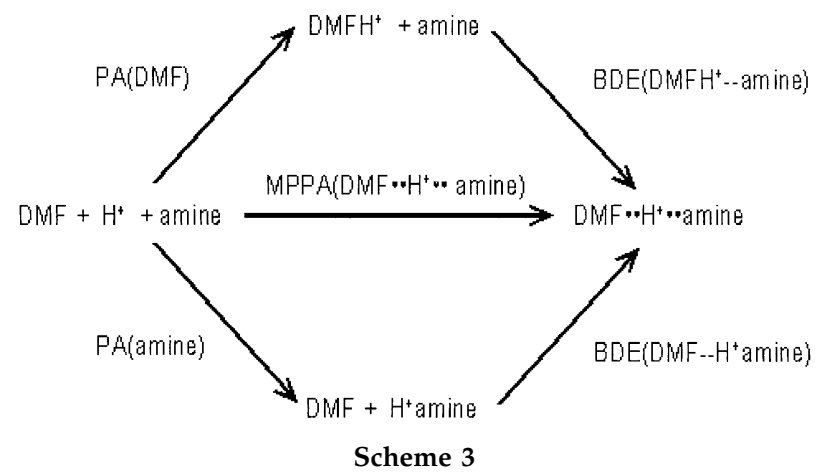

and the neutral ligand regardless of the relative GB and PA of the components. The BDE(DMF- $\mathrm{H}^{+}$ligand) of the other bond of some proton bound heterodimers of DMF, which corresponds to a dissociation into neutral DMF and the protonated base (Scheme 3), was determined previously by CERMS [6, 12]. Naturally, this is only possible for heterodimers containing ligands which are stronger bases than DMF. If the ligand is also a tertiary amide, the $\mathrm{D}\left(\mathrm{DMF}-\mathrm{H}^{+}\right.$ligand) decreases with increasing GB(ligand) while in the case of amines no simple dependence on GB(amine) is observed. Apparently the number of hydrogen atoms at the amino group has also an effect. The opposite variation of the strength of the two bonds of the proton bridge in the proton bound dimers, which is observed as a general trend, has to be expected if the proton bridge becomes more asymmetric with increasing GB of the components. Asymmetric proton bonds in proton bound heterodimers and even in homodimers have been proposed earlier and substantiated by ab-initio calculations [22]. Generally it is assumed that the dissociation energy of a proton bound heterodimer decreases with the difference PA (or GB) of the components and that the dissociation energy of a homodimer is particularly large. This rule is only partially followed by the dimers of amides. In particular, the dissociation energy of the symmetric proton bound homodimer $\left[\mathrm{DMF} \cdot \mathrm{H}^{+} \cdot \mathrm{DMF}\right.$ ] is not especially large but fits into the general correlation with $\mathrm{GB}$ (ligand). For example, the $\mathrm{D}\left(\mathrm{DMFH}^{+}\right.$ligand) of the heterodomer of DMF (GB $855 \mathrm{~kJ} / \mathrm{mol}$ ) and DMSO (GB $854 \mathrm{~kJ} / \mathrm{mol}$ ) and of the homodimer of DMF are identical within the limits of error.

As mentioned before, the $\mathrm{BDE}\left(\mathrm{DMF}-\mathrm{H}^{+}\right.$ligand) has been determined for several ligands independently by 


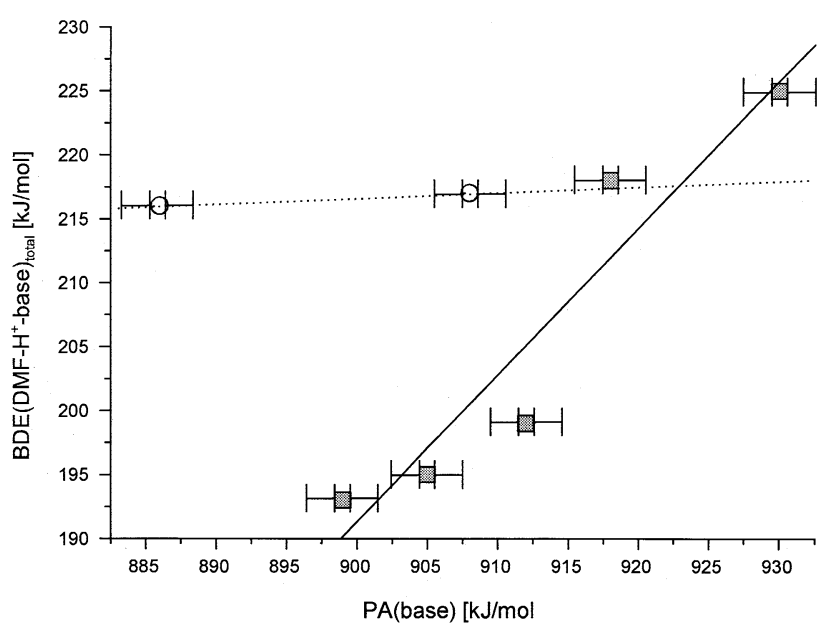

Figure 5. Correlation of bond dissociation energy BDE(DMF-

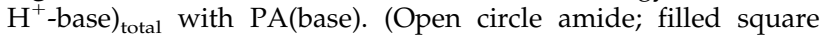
amine).

observing the dissociation into DMF and the protonated ligand by CERMS. Using these data and the $\mathrm{BDE}\left(\mathrm{DMFH}^{+}\right.$-ligand) of the other pertinent proton bond listed in Table 2, the total bond energy $\mathrm{D}_{\text {total }}$ for breaking simultaneously both bonds of the proton bridge can be obtained. The $\mathrm{BDE}\left(\mathrm{DMF}-\mathrm{H}^{+} \text {-ligand }\right)_{\text {total }}$ for 7 proton bound dimers of DMF are shown in the last column of Table 2, and the dependence on the PA of the components is shown in Figure 5. Only one other value is available for the $\mathrm{BDE}\left(\mathrm{DMF}-\mathrm{H}^{+} \text {-ligand) }\right)_{\text {total }}$ of a proton bound heterodimer of DMF with another amide besides the BDE(DMF- $\mathrm{H}^{+}$-ligand $)_{\text {total }}$ of the homodimer of DMF, but it is striking that the values of these two are identical within the limits of error in spite of a significant $\Delta \mathrm{PA}$ of $22 \mathrm{~kJ} / \mathrm{mol}$ between DMF and DMA. This may be another piece of evidence that the proton bridge between a polar amide and another polar ligand is special. In the case of the proton bridge of heterodimers of DMF and amines Figure 5 reveals that $\mathrm{BDE}\left(\mathrm{DMF}-\mathrm{H}^{+} \text {-ligand }\right)_{\text {total }}$ exhibits a linear dependence on the $\mathrm{GB}$ (amine) and increases considerably with $\triangle \mathrm{GB}$ of DMF and the amine. Thus, for dimethyl amine, which was used here as the strongest base, $\mathrm{D}\left(\mathrm{DMF}-\mathrm{H}^{+} \text {-ligand }\right)_{\text {total }}$ is greater than for the proton bound homodimer of DMF. This effect is due to the distinct increase of the $\mathrm{BDE}\left(\mathrm{DMFH}^{+}\right.$-amine) with increasing PA, which more than compensates for the decrease of $\mathrm{BDE}\left(\mathrm{DMF}-\mathrm{H}^{+}\right.$amine). Further, if compared to $\mathrm{BDE}\left(\mathrm{DMF}-\mathrm{H}^{+} \text {-ligand }\right)_{\text {total }}$ of the proton bound dimer of DMF and DMA, at the same PA, the BDE(DMF- $\mathrm{H}^{+}-$ ligand) $)_{\text {total }}$ of the proton bound dimer of DMF and an amine is about $20 \mathrm{~kJ} / \mathrm{mol}$ weaker.

\section{Conclusion}

One interesting result of the present study of the equilibria between proton bound homo- and heterodimers of DMF and other simple amides or amines in the gas phase is the observation that the proton bound dimers involving only polar ligands (amides, DMSO) behave differently compared to those including a non-polar basic ligand (amines). Starting with the proton bound homodimer $\left[\mathrm{DMF} \cdot \mathrm{H}^{+} \cdot \mathrm{DMF}\right]$, in the former case a two-step ligand exchange and an equilibrium between the three possible proton bound dimers is observed. In the latter case, only one DMF ligand is substituted by the non-polar ligand, and in the case of primary and secondary amines the proton bound heterodimer formed by this exchange reacts further by association of a second molecule DMF to generate a proton bound trimer. A relative free ligand affinity $\Delta \mathrm{G}_{\mathrm{DMFH}+}$ (base) and ligand affinity $\Delta \mathrm{A}_{\mathrm{DMFH}+}$ (base) of the base towards protonated DMF was derived from the equilibrium constants $K_{1}$ to characterize the proton bound dimers of DMF and a second base. This affinity reflects the binding of a ligand to $\mathrm{DMFH}^{+}$relative to DMF and depends on the difference $\triangle G B$ between ligand and DMF. Two linear correlations $\Delta \mathrm{G}_{\mathrm{DMFH}+}=0.44 \mathrm{~GB}$ (base) $-375[\mathrm{~kJ} /$ $\mathrm{mol}]$ and $\Delta \mathrm{G}_{\mathrm{DMFH}+}=0.46 \mathrm{~GB}$ (base) $-397[\mathrm{~kJ} / \mathrm{mol}]$ are observed for the series of polar and non-polar ligands, respectively, underlining the difference between polar and non-polar molecules as a partner in proton bound dimers with DMF. Further, $\Delta G_{D M F H}+$ and the molecular pair gas phase basicity MPGB(DMF) have been used to calculate MPGBs of the other molecular pairs DMF/base used in this study and to estimated dissociation energy $\mathrm{D}\left(\mathrm{DMFH}^{+}-\right.$ base) of the proton bridge. These data show also that a proton bridge between an amide and a polar ligand is different from that involving relatively non-polar amines. This is explained by a more or less symmetrical proton bridge between DMF and another amide or a polar ligand, while the proton bound heterodimer of DMF with an amine contains an asymmetric proton bridge and resembles more a protonated amine solvated by one (or two) DMF as a polar solvent. However, it is clear from the differences between proton bound heterodimers of DMF with primary or secondary amines on the one side and tertiary amines on the other side that some kind of a hydrogen (or proton) bond is still important in these "solvated" species. It will be shown in forthcoming papers that the differences between the proton bound heterodimers of amides containing non-polar and polar ligands are even more pronounced in the dynamics of the ligand exchange process.

\section{Acknowledgments}

The authors gratefully acknowledge financial assistance of the work by a grant from the Deutsche Forschungsgemeinschaft. The FT-ICR instrument used in this work was also granted by the Deutsche Forschungsgemeinschaft. The authors thank the Fonds der Chemischen Industrie for additional financial support and Dipl. ing. grad. M. Terrey for technical assistance in FT-ICR spectrometry. 


\section{References}

1. Franks, F. Characterization of Proteins. Humana Press: Clifton, 1988.

2. (a) Fersht, A. R. Enzyme Structure and Mechanism; 2nd ed. Freeman: New York, 1985. (b) Kirby, A. J. Efficiency of Proton Transfer Catalysis in Models and Enzymes. Acc. Chem. Res. 1997, 30, 290-296.

3. (a) Green, M. K.; Lebrilla, C. B. Ion-Molecule Reactions as Probes of Gas-Phase Structures of Peptides and Proteins. Mass Spectrom. Rev. 1997, 16, 53-71. (b) Carr, S. A.; Hemling, M. E.; Bean, M. F.; Roberts, G. R. Integration of Mass Spectrometry in Analytical Biotechnology. Anal. Chem. 1991, 63, 2802-2824. (c) Fenselau, C. MALDI-MS and Strategies for Protein Analysis. Anal. Chem. 1997, 69, 661A-665A.(d)Jarrold, M. F. Peptides and Proteins in the Gas Phase. Annu. Rev. Phys. Chem. 2001, 51, 179-207.

4. (a) Campbell, S.; Rodgers, M. T.; Marzluff, E. M.; Beauchamp, J. L. Deuterium Exchange as a Probe of Biomolecule Structure. Fundamental Studies of Gas Phase H/D Exchange Reactions of Protonated Glycine Oligomers with $\mathrm{D}_{2} \mathrm{O}, \mathrm{CD}_{3} \mathrm{OD}$, $\mathrm{CD}_{3} \mathrm{CO}_{2} \mathrm{D}$, and $\mathrm{ND}_{3}$. J. Am. Chem. Soc. 1995, 117, 12840-12854. (b) Przybylski, M.; Glocker, M. O. Elektrospray-Massenspektrometrie von Biomolekülkomplexen mit nichtkovalenten Wechselwirkungen-neue analytische Perspektiven für supramolekulare Chemie und molekulare Erkennungsprozesse. Angew. Chem. 1996, 108, 878-899; and Angew. Chem. Int. Ed. Engl. 1966, 35, 806-826.. (c) Wyttenbach, T.; Bowers, M. T. Gas Phase Conformations of Biological Molecules: The Hydrogen/ Deuterium Exchange Mechanism. J. Am. Soc. Mass Spectrom. 1999, 10, 9-14. (d) Jarrold, M. F. Unfolding, Refolding, and Hydration of Proteins in the Gas Phase. Acc. Chem. Res. 1999, 32, 360-367. (e) McLafferty, F. W.; Cuan, Z.; Haupts, U.; Wood, T. D.; Kelleher, N. L. Gaseous Conformational Structures of Cyctochrome c.. J. Am. Soc. Chem. 1998, 120, 4732-4740.

5. (a) Meot-Ner (Mautner), M. The Ionic Hydrogen Bond. IV. Intramolecular and Multiple Bonds. Protonation and Complexes of Amides and Amino Acids Derivatives. J. Am. Chem. Soc. 1984, 106, 278-283. (b) Meot-Ner (Mautner), M. Models for Strong Interaction in Proteins and Enzymes. II. Interactions of Ions with the Peptide Link and with Imidazole. J. Am. Chem. Soc. 1988, 110, 3075-3080.

6. (a) Witt, M.; Grützmacher, H.-F. The Gas Phase Basicity and Proton Affinity of Propionamide. A Comparison of Methods. Int. J. Mass Spectrom. 1997, 164, 93-106. (b) Witt, M.; Grützmacher, H.-F. Proton-Bound Dimers of Aliphatic Carboxamides: Gas-Phase Basicity and Dissociation Energy. Int. J. Mass Spectrom. 1997, 165/166, 49-62.

7. Witt, M.; Grützmacher, H.-F. Effects of Internal Hydrogen Bonds Between Carboxamide Groups: Gas-Phase Basicity and Proton Affinity of Linear Aliphatic Diamides. Eur. Mass Spectrom. 2000, 6, 97-107.

8. (a) Cooks, R. G.; Kruger, T. L. Intrinsic Basicity Determination Using Metastable Ions. J. Am. Chem. Soc. 1977, 99, 1279-1281. (b) Cooks, R. G.; Pattrick, J. S.; Kotiaho, T.; McLuckey, S. A. Thermochemical Determinations by the Kinetic Method. Mass Spectrom. Rev. 1994, 13, 287-339. (c) Cooks, R. G.; Koskinen, J. T.; Thomas, P. D. The Kinetic Method of Making Thermochemical Determinations. J. Mass Spectrom. 1999, 34, 85-92.

9. Sievers, H. L.; Caravatti, P.; Grützmacher, H.-F. The Geometry Factor of Infinitely Long Cylindrical ICR Cell for Collision
Energy Resolved Mass Spectrometry (CERMS): Appearance Energies of $\mathrm{EI}_{2}^{+}$from $\mathrm{EI}_{3}^{+\cdot}$ and $\left[\mathrm{EI}_{2} \cdot \text { Ligand }\right]^{+}$Complexes $(\mathrm{E}=$ P, As, Sb, Bi). Int. J. Mass Spectrom. Ion Processes 1996, 157/158, 233-247.

10. Rodgers, M. T.; Armentrout, P. B. Noncovalent Metal-Ligand Bond Energies as Studied by Threshold Collision-Induced Dissociation. Mass Spectrom. Rev. 2001, 19, 215-247.

11. (a) Larson, J. W.; McMahon, T. B. Formation, Thermochemistry and Relative Stabilities of Proton-Bound Dimers of Oxygen n-Donor Bases from Ion Cyclotron Resonance Solvent-Exchange Equilibria Measurements. J. Am. Chem. Soc. 1982, 104, 6255-6261. (b) Cao, J.; Holmes, J. L. The Determination of Proton Affinities of Secondary Alcohols from the Dissociation of Proton Bound Molecular Trios. Eur. J. Mass Spectrom. 2001, 7, 243-246.

12. Witt, M. Dissertation, (Gasphasenreaktionen protonengebundener Amidcluster); Universität Bielefeld, 1998.

13. Witt, M.; Grützmacher, H.-F. Ligand Exchange Reactions of Proton Bound Dimers of Carboxamides-Models for Protonated Proteins. Int. J. Mass Spectrom., in press.

14. (a) Allemann, M.; Kellerhals, H. P.; Wanczek, K. P. High Magnetic Field Fourier Transform Ion Cyclotron Resonance Spectroscopy. Int. J. Mass Spectrom. Ion Processes 1983, 46, 139-142. (b) Kofel, P.; Allemann, M.; Kellerhals, H. P.; Wanczek, K. P. External Generation of Ions in ICR Spectrometry. Int. J. Mass Spectrom. Ion Processes 1985, 65, 97-103.

15. Caravatti, P.; Alleman, M. The "Infinity Cell:" A New Trapped-Ion Cell With Radio-Frequency Covered Trapping Electrodes for Fourier Transform Ion Cyclotron Resonance Mass Spectrometry. Org. Mass Spectrom. 1991, 26, 514-518.

16. Microcal Origin 4.1, Microcal Software Inc.: Northampton, MA, 1996.

17. Anicich, V. G. Evaluated Bimolecular Ion-Molecule Gas Phase Kinetics of Positive Ions for Use in Modeling Planetary Atmosphere, Cometary Comae, and Interstellar Clouds. J. Phys. Chem. Ref. Data 1993, 22, 1469-1569.

18. Bartmess, J. E.; Georgiadis, R. M. Empirical Methods for Determination of Ionization Gauge Relative Sensitivities for Different Gases. Vacuum 1983, 33, 149-153.

19. Witt, M.; Grützmacher, H.-F. to be published.

20. All GB and PA were taken from NIST Standard Reference Database No. 69 - Release February 2000 (http//webbook. nist.gov./chemistry).

21. (a) Davidson, W. R.; Sunner, J.; Kebarle, P. Hydrogen Bonding of Water to Onium ions. Hydration of Substituted Pyridinium Ions and related Systems. J. Am. Chem. Soc. 1979, 101, 1675. (b) Meot-Ner (Mautner), M. The Ionic Hydrogen Bond. II. Protonation and Complexes of Amines, Alcohol, and Ethers. J. Am. Chem. Soc. 1984, 106, 1257. (c) Speller, C. V.; Meot-Ner (Mautner), M. The Ionic Hydrogen Bond and Ion Solvation. III. Bonds Involving Cyanides. Correlations with Proton Affinities. J. Phys. Chem. 1985, 89, 5217.

22. (a) Scheiner, S.; Wang, L. Hydrogen Bonding and Proton Transfers of the Amide Group. J. Am. Chem. Soc. 1993, 115, 1958-1963. (b) Scheiner, S. Bent Hydrogen Bonds and Proton Transfers. Acc. Chem. Res. 1994, 27, 402-408. (c) Perrin, C. L. Proton Exchange in Amides: Surprises from Simple Systems. Acc. Chem. Res. 1989, 22, 268-275. (d) Perrin, C. L.; Nielson, J. B. "Strong" Hydrogen Bonds in Chemistry and Biology. Ann. Rev. Phys. Chem. 1997, 48, 511-544. 